\title{
Emerging Therapies for Diabetic Nephropathy Patients: Beyond Blockade of the Renin-Angiotensin System
}

\author{
Bassem Y. Tanios Fuad N. Ziyadeh \\ Department of Internal Medicine, American University of Beirut, Beirut, Lebanon
}

\section{Key Words}

Diabetes mellitus $\cdot$ Chronic kidney disease $\cdot$ Diabetic nephropathy therapy $\cdot$ Drug therapy $\cdot$

Novel agents

\begin{abstract}
Diabetic nephropathy is a leading cause of end-stage renal disease worldwide. The mainstay of treatment has been glycemic control and blood pressure lowering using agents blocking the renin-angiotensin system. Clinical trials are currently under way using novel agents for the treatment of patients with diabetic nephropathy. Promising agents emerging from some of the completed trials include pirfenidone and bardoxolone methyl, which have been shown in two recent randomized controlled trials in patients with diabetic nephropathy to result in an improved estimated glomerular filtration rate compared to placebo. Also, paricalcitol has been shown to decrease the urinary albumin-to-creatinine ratio, whereas sulodexide failed to do so in a large randomized double-blind placebo-controlled trial. Of note, pyridoxamine has also shown promise in the treatment of diabetic nephropathy if started early in the disease course. These preliminary trials have shown significant promise for managing patients with diabetic nephropathy, sparking active research in this field and providing the rationale for further clinical testing in long-term, hard-outcomes trials.

Copyright $\odot 2012$ S. Karger AG, Basel
\end{abstract}

Prof. Fuad N. Ziyadeh, MD, FASN, FACP Department of Internal Medicine

American University of Beirut Medical Center, PO Box 11-0236

Riad El-Solh, Beirut 11072020 (Lebanon)

E-Mail fz05@aub.edu.lb 


\section{Introduction}

Diabetic nephropathy is the most common cause of glomerulosclerosis and end-stage renal disease (ESRD) [1]. Between 20 and $40 \%$ of patients with diabetes mellitus ultimately develop nephropathy [2]. The standard of care for diabetic nephropathy has been blood pressure control, the use of renin-angiotensin system-blocking agents such as angiotensin-converting enzyme inhibitors (ACEIs) and angiotensin receptor blockers (ARBs), and tight glycemic control [3]. However, current therapeutic strategies are far from being completely effective because no available therapy successfully prevents diabetic nephropathy and many patients still progress to ESRD.

In a recent short-term study, the direct renin inhibitor aliskiren held promise as it further reduced the urinary albumin-to-creatinine ratio (ACR) when added to losartan [4]; however, the long-awaited ALTITUDE trial examining the effects of aliskiren when added to ACEI/ARB on long-term renal and cardiovascular outcomes has been recently halted because of an increased incidence of adverse events including nonfatal strokes in the aliskiren group [5]. Therefore, there is need for new therapies that would target other primary mechanisms that are implicated in the pathogenesis of diabetic nephropathy. In fact, recent advances in the understanding of the pathophysiologic mechanisms of diabetic kidney disease have led to the clinical development of new therapeutic agents, many of which are currently the subject of ongoing clinical trials.

In this review, we focus on some of the recently completed clinical trials involving novel drugs that hold promise for the management of diabetic nephropathy.

\section{Pirfenidone}

Pirfenidone is an orally bioavailable compound that has been found to inhibit transforming growth factor- $\beta$ (TGF- $\beta$ ) production and consequent matrix deposition in experimental animal models of lung and kidney disease [6]. In a recent randomized double-blind placebo-controlled trial [7], 77 subjects with diabetes, reduced estimated glomerular filtration rate (eGFR), and proteinuria were enrolled and randomized to one of the three study arms (placebo, pirfenidone 1,200 $\mathrm{mg}$ daily, and pirfenidone 2,400 mg daily). The primary end point was the change in eGFR in individual subjects from baseline to the end of the study. After 54 weeks, there was an improvement in eGFR in the pirfenidone 1,200 mg group, with a net increase of $3.3 \mathrm{ml} / \mathrm{min} / 1.73 \mathrm{~m}^{2}$. The pirfenidone $2,400 \mathrm{mg}$ group had an intermediate change in eGFR $\left(-1.9 \mathrm{ml} / \mathrm{min} / 1.73 \mathrm{~m}^{2}\right)$ that was not significantly different compared with the placebo arm. Interestingly, there were no significant differences among the study groups in the change in urinary ACR from baseline to the end of the study.

Limitations of the above study included the lack of hard renal and clinical end points such as progression to ESRD and death, a high dropout rate due to gastrointestinal side effects in the pirfenidone groups (which could explain the lack of efficacy in the higher dose of pirfenidone in this trial), the absence of direct measurements of GFR, and a small sample size.

Nevertheless, these results clearly show that pirfenidone may be a promising agent for preventing decline in, or even improving, kidney function in diabetic nephropathy; however, larger-scale trials with hard clinical and renal outcomes are needed to confirm these findings. 


\section{Bardoxolone Methyl}

Bardoxolone methyl, a derivative of the natural product oleanolic acid, is an antioxidant inflammation modulator that can activate the Keap1-Nrf2 pathway, which leads to inhibition of the proinflammatory nuclear factor- $\kappa \mathrm{B}$ pathway [8].

In a recent randomized double-blind placebo-controlled trial [9], the effects of three doses of bardoxolone methyl on eGFR in patients with type 2 diabetes and chronic kidney disease were assessed at 24 and 52 weeks. A total of 227 patients were randomly assigned to receive placebo or oral bardoxolone methyl at a dose of 25,75 , or $150 \mathrm{mg}$ once daily for 52 weeks.

At 24 weeks, there was a significant improvement in the primary end point (change in eGFR from baseline) in all bardoxolone methyl groups, as compared with the placebo group, with mean differences of $8.2 \mathrm{ml} / \mathrm{min} / 1.73 \mathrm{~m}^{2}$ in the $25 \mathrm{mg}$ group, $11.4 \mathrm{ml} / \mathrm{min} / 1.73 \mathrm{~m}^{2}$ in the $75 \mathrm{mg}$ group, and $10.4 \mathrm{ml} / \mathrm{min} / 1.73 \mathrm{~m}^{2}$ in the $150 \mathrm{mg}$ group. Four weeks after the last administration of the study drug (at 56 weeks), the eGFR remained above the baseline value in patients receiving bardoxolone methyl. In the $75 \mathrm{mg}$ and $150 \mathrm{mg}$ groups, there was a slight but significant increase in the urinary ACR at 24 and 52 weeks. At 56 weeks, the ACR returned to the baseline level.

Again, one major limitation of this trial is the reliance on the surrogate primary end point (the change in eGFR) rather than direct renal clearance measurements.

Nevertheless, these results also clearly show that bardoxolone methyl may be a useful agent for the therapy of diabetic nephropathy. The confirmation of its clinical benefit will require a larger long-term study involving the assessment of various clinical outcomes. In October 2012, the late-stage trial BEACON of bardoxolone therapy was halted after an independent data-monitoring committee found excess serious adverse events and mortality in patients taking the drug.

\section{Sulodexide}

Diabetic nephropathy is associated with a decrease in the glycosaminoglycan composition of the glomerular basement membrane, particularly heparan sulfate. This loss of glomerular basement membrane integrity may aggravate proteinuria, and this may accelerate the progression of renal disease [10]. Sulodexide is a glycosaminoglycan extract of the porcine lung and liver; the primary components are low-molecular-weight heparin sulfate and dermatan sulfate. Some preliminary data suggested that orally administered sulodexide was capable of reducing urine albumin excretion in diabetic patients $[11,12]$. However, in a large randomized double-blind placebo-controlled trial [13] involving 1,056 subjects with type 2 diabetes mellitus and microalbuminuria, sulodexide at a dose of $200 \mathrm{mg}$ per day failed to decrease urine albumin excretion compared with placebo.

\section{Pyridoxamine}

Pyridoxamine, a vitamin B6 derivative, is an effective scavenger of reactive oxygen species and a potent inhibitor of advanced glycation end products [14]. In a double-blind randomized placebo-controlled study [15], the efficacy of pyridoxamine dihydrochloride in delaying the progression of diabetic nephropathy was assessed. A total of 317 patients were randomly assigned to receive placebo, pyridoxamine dihydrochloride $150 \mathrm{mg}$ twice daily, or pyridoxamine dihydrochloride $300 \mathrm{mg}$ twice daily for 52 weeks. At the onset of the study, 
the mean serum creatinine level was $2.2 \mathrm{mg} / \mathrm{dl}$, and the mean protein-to-creatinine ratio was $2,973 \mathrm{mg} / \mathrm{g}$. The primary end point of the study was the change in the serum creatinine level from baseline.

At the end of the study period, there was no statistically significant difference in serum creatinine among the three groups. However, in the subgroup analysis, a significant treatment effect was noted for patients with mild renal impairment (serum creatinine 1.3-1.85 $\mathrm{mg} / \mathrm{dl}$ ) for both pyridoxamine dihydrochloride groups versus the placebo group.

The possibility that diabetic patients with less severe kidney impairment may benefit from pyridoxamine therapy remains to be investigated in an adequately powered trial addressing this specific subpopulation.

\section{Paricalcitol}

Paricalcitol, a calcitriol analogue, is a vitamin D receptor activator. In animal models, activation of the vitamin D receptor suppressed TGF- $\beta$, reduced albuminuria, and slowed progression of kidney disease [16]. In a recent multinational placebo-controlled double-blind study [17], 281 diabetic patients with albuminuria were randomized to 24 weeks of treatment with paricalcitol 1 or $2 \mu \mathrm{g} /$ day or placebo in addition to pre-existing ACEI or ARB therapy. At the end of the study period, the $2-\mu \mathrm{g}$ dose was associated with a $20 \%$ decline in the urinary ACR compared to placebo.

Although the results of this study are encouraging, the clinical value of paricalcitol and other selective vitamin $\mathrm{D}$ receptor activators in the management of diabetic nephropathy will need to be confirmed by a larger prospective randomized trial with a longer duration, assessing effects on hard renal and cardiovascular outcomes.

\section{Conclusions}

The encouraging results of some of the discussed agents will surely spark active research in this field, testing the above agents in long-term, hard-outcomes trials, like the BEACON trial [18], or other agents targeting other primary pathogenic mechanisms in diabetic nephropathy using antifibrotic agents such as anti-connective tissue growth factor monoclonal antibody [19] or anti-TGF- $\beta$ monoclonal antibody [20]. Hopefully, we can fulfill the dream of significantly decreasing the burden of kidney disease in patients with diabetes mellitus by preventing, delaying, arresting, or even improving diabetic nephropathy [20].

\section{References}

1 Held PJ, Port FK, Webb RL, Wolfe RA, Garcia JR, Blagg CR, Agodoa LY: The United States Renal Data System's 1991 annual data report: an introduction. Am J Kidney Dis 1991;18:1-16.

2 Dronavalli S, Duka I, Bakris GL: The pathogenesis of diabetic nephropathy. Nat Clin Pract Endocrinol Metab 2008;4:444-452.

3 American Diabetes Association: Standards of medical care in diabetes - 2011. Diabetes Care 2011; 34:S11-S61.

4 Parving HH, Persson F, Lewis JB, Lewis EJ, Hollenberg NK, AVOID Study Investigators: Aliskiren combined with losartan in type 2 diabetes and nephropathy. N Engl J Med 2008;358:2433-2446. 


\begin{tabular}{|c|c|}
\hline Nephron Extra 2012;2:278-282 & \\
\hline $\begin{array}{l}\text { DOI: } 10.1159 / 000343312 \\
\text { Published online: October 30, } 2012\end{array}$ & $\begin{array}{l}\text { @ } 2012 \text { S. Karger AG, Basel } \\
\text { www.karger.com/nne }\end{array}$ \\
\hline
\end{tabular}

5 Novartis Media Releases December 20, 2011. http://www.novartis.com/newsroom/media-releases/ en/2011/1572562.shtml.

-6 RamachandraRao SP, Zhu Y, Ravasi T, McGowan TA, Toh I, Dunn SR, Okada S, Shaw MA, Sharma K: Pirfenidone is renoprotective in diabetic kidney disease. J Am Soc Nephrol 2009;20:1765-1775.

-7 Sharma K, Ix JH, Mathew AV, Cho M, Pflueger A, Dunn SR, Francos B, Sharma S, Falkner B, McGowan TA, Donohue M, Ramachandrarao S, Xu R, Fervenza FC, Kopp JB: Pirfenidone for diabetic nephropathy. J Am Soc Nephrol 2011;22:1144-1151.

-8 Straus DS, Pascual G, Li M, Welch JS, Ricote M, Hsiang CH, Sengchanthalangsy LL, Ghosh G, Glass CK: 15-deoxy-delta 12,14-prostaglandin J2 inhibits multiple steps in the NF-kappa B signaling pathway. Proc Natl Acad Sci USA 2000;97:4844-4849.

-9 Pergola PE, Raskin P, Toto RD, Meyer CJ, Huff JW, Grossman EB, Krauth M, Ruiz S, Audhya P, Christ-Schmidt H, Wittes J, Warnock DG, BEAM Study Investigators: Bardoxolone methyl and kidney function in CKD with type 2 diabetes. N Engl J Med 2011;365:327-336.

10 Parthasarathy N, Spiro RG: Effect of diabetes on the glycosaminoglycan component of the human glomerular basement membrane. Diabetes 1982;31:738-741.

-11 Shimomura H, Spiro BG: Studies on macromolecular components of human glomerular basement membrane and alterations in diabetes. Decreased levels of heparin sulfate proteoglycan and laminin. Diabetes 1987;36:374-381.

-12 Solini A, Vergnani L, Ricci F, Crepaldi G: Glycosaminoglycans delay the progression of nephropathy in NIDDM. Diabetes Care 1997;20:819-823.

-13 Lewis EJ, Lewis JB, Greene T, Hunsicker LG, Berl T, Pohl MA, de Zeeuw D, Heerspink HL, Rohde RD, Atkins RC, Reutens AT, Packham DK, Raz I, Collaborative Study Group: Sulodexide for kidney protection in type 2 diabetes patients with microalbuminuria: a randomized controlled trial. Am J Kidney Dis 2011;58:729-736.

-14 Voziyan PA, Hudson BG: Pyridoxamine as a multifunctional pharmaceutical: targeting pathogenic glycation and oxidative damage. Cell Mol Life Sci 2005;62:1671-1681.

- 15 Lewis EJ, Greene T, Spitalewiz S, Blumenthal S, Berl T, Hunsicker LG, Pohl MA, Rohde RD, Raz I, Yerushalmy Y, Yagil Y, Herskovits T, Atkins RC, Reutens AT, Packham DK, Lewis JB, Collaborative Study Group: Pyridorin in type 2 diabetic nephropathy. J Am Soc Nephrol 2012;23:131-136.

- 16 Mizobuchi M, Morrissey J, Finch JL, Martin DR, Liapis H, Akizawa T, Slatopolsky E: Combination therapy with an angiotensin-converting enzyme inhibitor and a vitamin D analog suppresses the progression of renal insufficiency in uremic rats. J Am Soc Nephrol 2007;18:1796-1806.

-17 de Zeeuw D, Agarwal R, Amdahl M, Audhya P, Coyne D, Garimella T, Parving HH, Pritchett Y, Remuzzi G, Ritz E, Andress D: Selective vitamin D receptor activation with paricalcitol for reduction of albuminuria in patients with type 2 diabetes (VITAL study): a randomised controlled trial. Lancet 2010;376:1543-1551.

18 Bardoxolone Methyl Evaluation in Patients With Chronic Kidney Disease and Type 2 Diabetes (BEACON). http://www.clinicaltrials.gov/show/NCT01351675.

-19 Adler SG, Schwartz S, Williams ME, Arauz-Pacheco C, Bolton WK, Lee T, Li D, Neff TB, Urquilla PR, Sewell KL: Phase 1 study of anti-CTGF monoclonal antibody in patients with diabetes and microalbuminuria. Clin J Am Soc Nephrol 2010;5:1420-1428.

-20 Ziyadeh FN, Sharma K: Overview: combating diabetic nephropathy. J Am Soc Nephrol 2003;14: 1355-1357. 